\title{
Preparation and Characterisation of Fe/Ce Multilayer
}

\section{H. DAWCZAK-DęBicki ${ }^{a, b, *}$, A. MARCzyńska ${ }^{a}$, S. PACANOWSKi $^{a}$, B. Szymański ${ }^{a}$,} Ł. MAjChrzYCKI ${ }^{c}$, W. KowAlski ${ }^{a}$, W. Grembowski ${ }^{a}$, T. Bilski ${ }^{a}$, And L. SMARdz $^{a}$ ${ }^{a}$ Institute of Molecular Physics, Polish Academy of Sciences, M. Smoluchowskiego 17, 60-179 Poznań, Poland ${ }^{b}$ Faculty of Physics, Adam Mickiewicz University, Umultowska 85, 61-614 Poznań, Poland ${ }^{c}$ WCZT, Adam Mickiewicz University, Umultowska 89C, 61-614 Poznań, Poland

$\mathrm{Ce} / \mathrm{Fe}$ multilayer $(\mathrm{ML})$ with constant $\mathrm{Fe}(2 \mathrm{~nm})$ and $\mathrm{Ce}(4.5 \mathrm{~nm})$ sublayer thicknesses was prepared onto naturally oxidised $\mathrm{Si}(100)$ substrate using magnetron sputtering. Chemical purity of the sublayers was revealed in-situ by X-ray photoelectron spectroscopy (XPS) measurements. The structure of the sample was studied by standard low- and high-angle X-ray diffraction (XRD). Surface morphology of the ML was examined by atomic force microscopy. Magnetic properties of the sample was studied in the temperature range between 5 and $350 \mathrm{~K}$ using a vibrating sample magnetometer in a magnetic field up to $9 \mathrm{~T}$. The hysteresis loops were measured in field perpendicular and parallel to the substrate. Furthermore, hydrogen absorption at a pressure of about 1000 mbar was studied at room temperature (RT) in Pd covered ML using four-point resistivity measurements. The solid state amorphisation reaction have been confirmed by XRD and magnetic measurements of the Ce/Fe ML. The absence of satellite peaks in the low - angle XRD pattern revealed no artificial layered structure. The above results show that interdiffusion of cerium and iron atoms is extremely fast at RT.

DOI: 10.12693/APhysPolA.133.628

PACS/topics: 75.70.-i, 68.55.--a

\section{Introduction}

It is well known that magnetic multilayers exhibit a rich variety of novel effects related to interface effects in ultrathin layers [1-3]. An important studies of magnetic layerd structures is the influence of a spacer layer inserted between two ferromagnetic layers. It has been shown that, depending on the thickness of the spacer layer, two ferromagnetic layers may be coupled parallel or antiparallel. Moreover, the induced magnetism of the spacer layer due to proximity effect has been also evidenced $[4,5]$.

In the layered $\mathrm{Fe} / \mathrm{Ce}$ structures, for a thickness smaller than $2.5 \mathrm{~nm}$, Ce adopts an $\alpha$-like electronic configuration with a magnetic order [6] in contrast to the $\alpha$ - phase of Ce metal which is nonmagnetic. While the magnetic ordering is relatively well understood for elemental rare earths, the $5 \mathrm{~d}$ magnetization of $\mathrm{Ce}$ is much more complex because of its $4 \mathrm{f}$ electronic states which are at the borderline between localization and itinerancy.

Light rare earth (RE) metals like La and Ce form a cubic dihydride $\mathrm{REH}_{2}$ with hydrogen atoms on tetrahedrally coordinated sites $\left(\mathrm{CaF}_{2}\right.$ - type structure) and dissolve, in a single phase, further hydrogen on octahedral sites up to the cubic trihydride $\mathrm{REH}_{3}\left(\mathrm{BiF}_{3}\right.$ - type structure) [7]. The hydrides $\mathrm{REH}_{x}$ undergo a transition from a metal to an insulator as the hydrogen content approaches $x=3$, with the accompanying change from high optical reflectivity to transparency for photon energies below $2 \mathrm{eV}$ [7]. The transition is continuous and reversible, and a thin film of such material allows to rapidly switch be-

*corresponding author; e-mail: dawczak@ifmpan.poznan.pl tween the contrasting optical properties of the dihydride and trihydride phase, simply by varying the surrounding hydrogen gas pressure or an electrolytic cell potential [8].

In this paper we study structure, morphology and interface alloying in $\mathrm{Fe} / \mathrm{Ce}$ multilayer (ML). Moreover, hydrogen absorption kinetics at a pressure of about 1000 mbar was measured at room temperature (RT) in $\mathrm{Pd}$ covered multilayered sample.

\section{Experimental procedure}

$\mathrm{Fe} / \mathrm{Ce} \mathrm{ML}$ was prepared at RT using ultra high vacuum (UHV) $\left(5 \times 10^{-10}\right.$ mbar) magnetron sputtering [9-11]. Schematic description of the prepared $\mathrm{Fe} / \mathrm{Ce} \mathrm{ML}$ is shown in Fig. 1. As a substrate we have used $\operatorname{Si}(100)$ wafers with naturally oxidised surface to prevent a silicide formation. Therefore we have applied a special heat treatment in UHV before deposition in order to obtain a smooth $\mathrm{SiO}_{x}$ surface layer. The Ce-layers $\left(d_{\mathrm{Ce}}=4.5 \mathrm{~nm}\right)$ were deposited using a radio frequency (RF) current source. For preparation of the Fe-layers $\left(d_{\mathrm{Fe}}=2 \mathrm{~nm}\right)$

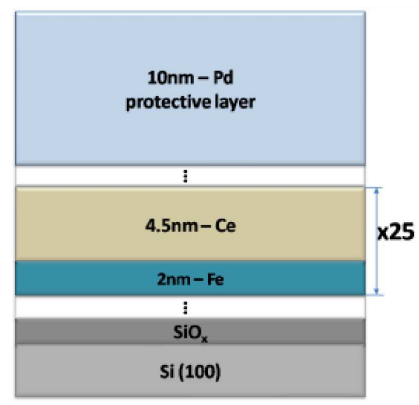

Fig. 1. Schematic description of the prepared $\mathrm{Fe} / \mathrm{Ce}$ multilayer. 
a direct current (DC) source was used. The deposition rates of Fe and Ce were individually checked by quartz thickness monitors. The thickness of individual layers were controlled by varying their deposition times. Furthermore, the calibrations of the deposition rates were also determined by thickness measurements of reference samples using DEC-TAC (Bruker) profilometer and Xray fluorescence analysis. The number of repetition was equal to 25. Finally, a protective layer of $10 \mathrm{~nm} \mathrm{Pd}$ was deposited to allow a fast uptake and release of hydrogen at RT and to avoid oxidation of the top Ce sublayer $[12,13]$.

The chemical composition of all the layers was checked in-situ, immediately after deposition, transferring the samples to an UHV $\left(4 \times 10^{-11}\right.$ mbar $)$ analysis chamber equipped with X-ray Photoelectron Spectroscopy (XPS). Details of the XPS measurements can be found in Ref. [14-16]. The XPS spectra were measured at RT using a SPECS EA 10 PLUS energy spectrometer with $\mathrm{Al}-\mathrm{K}_{\alpha}$ radiation of $1486.6 \mathrm{eV}$. The energy spectra of the electrons were analysed by a hemispherical analyser $\left(\mathrm{FWHM}_{\mathrm{Mg}-\mathrm{K} \alpha}=0.8 \mathrm{eV}\right.$ for $\left.\mathrm{Ag}-3 d_{5 / 2}\right)$. All emission spectra were measured immediately after the sample transfer in vacuum of $8 \times 10^{-11}$ mbar. The structure of the $\mathrm{Fe} / \mathrm{Ce} \mathrm{ML}$ was examined using standard $\theta-2 \theta \mathrm{X}$ ray diffraction (XRD). Hydrogen loading was performed in the HV chamber evacuated to about $10^{-6}$ mbar.

Absorption kinetics at a pressure of about 1000 mbar was studied at $\mathrm{RT}$ in $\mathrm{Pd}$ covered $\mathrm{Fe} / \mathrm{Ce} \mathrm{ML}$ using fourpoint resistivity measurements. The above procedure does not change the hysteresis loop of the "as prepared" sample.

The magnetic characterisation of the ML was carried out using a Vibrating Sample Magnetometer (VSM) in the temperature range $5 \div 350 \mathrm{~K}$ in an in-plane and perpendicular magnetic field up to $9 \mathrm{~T}$.

\section{Results and discussion}

XPS core-level spectra for the freshly prepared $2 \mathrm{~nm} \mathrm{Fe}$ and $4.5 \mathrm{~nm}$ Ce thin films are shown in Fig. 2. As can be observed, the impurities are absent on the surfaces of such prepared thin films. Practically no XPS signal from potential contamination atoms like $\mathrm{O}-1 \mathrm{~s}$ and $\mathrm{C}-1 \mathrm{~s}$ was observed.

In Fig. 3 we show AFM image $(300 \times 300[\mathrm{~nm}])$ of $\mathrm{Pd}$ covered Fe/Ce ML measured at RT. The Pd grains show an in-plane texture because the magnetron sources are mounted at an angle of about $60 \mathrm{deg}$ to the substrate. However, the surface of the ML is very smooth. We have estimated an average roughness parameter $R_{a}$ from a greater area $(2000 \times 2000[\mathrm{~nm}])$ as small as $0.22 \mathrm{~nm}$.

Figure 4 shows low- and high-angle XRD patterns of the $\mathrm{Fe} / \mathrm{Ce} \mathrm{ML}$. The positions of the observed reflections (Fig. 4a) reveal formation of an amorphous alloy due to solid state reaction already during the sample growth process at RT. The above result is in good agreement with earlier studies reported in Ref. [17]. In the highangle diffraction pattern (Fig. 4b) we have observed the

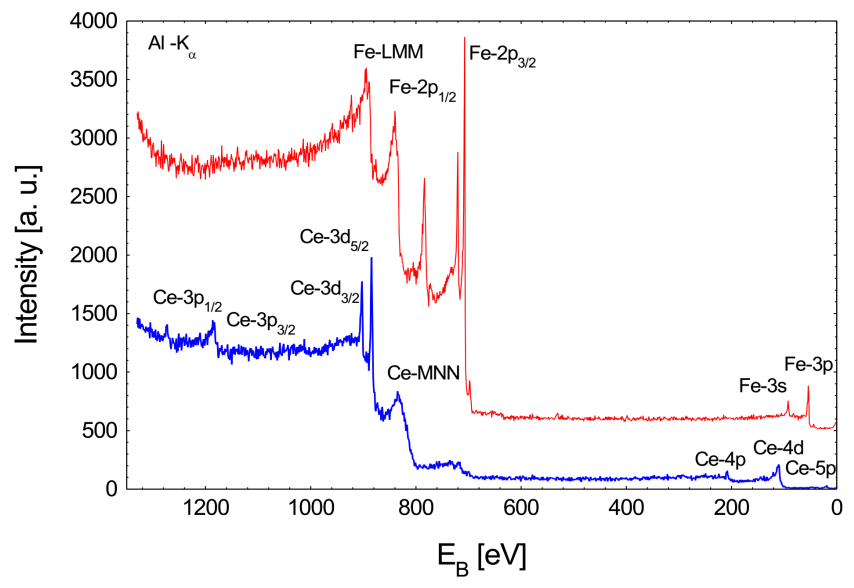

Fig. 2. XPS (Al-K $)_{\alpha}$ spectra of in-situ prepared $2 \mathrm{~nm} \mathrm{Fe}$ and $4.5 \mathrm{~nm}$ Ce thin films.

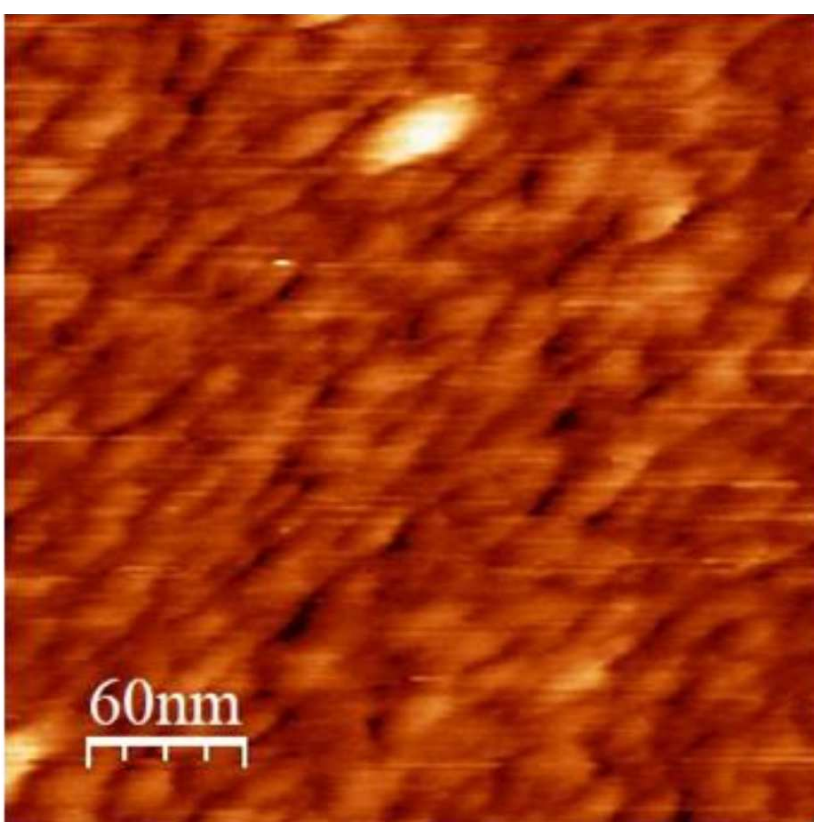

Fig. 3. AFM image of $(2 \mathrm{~nm} \quad \mathrm{Fe} / 4.5 \mathrm{~nm} \quad \mathrm{Ce}) \times$ $25 / 10 \mathrm{~nm}$ Pd ML. Average roughness parameter $R_{a}$ was estimated as about $0.22 \mathrm{~nm}$.

only one peak near 40 deg originated from textured $\mathrm{Pd}$ protective layer. Other XRD signal between 30 and 35 deg originates from oxidised Si substrate as shown in Fig 4b. We also haven't observed typical for crystalline MLs central Bragg peak because formation of an amorphous Fe-Ce alloy due to solid state reaction [18].

The hysteresis loops measured for Fe/Ce ML in an inplane and perpendicular to the substrate magnetic field are shown in Fig. 5a and Fig. 5b, respectively. The measurements were performed at $5 \mathrm{~K}$ (solid line) and $300 \mathrm{~K}$ (broken line). The relatively high drop of the saturation magnetisation at $300 \mathrm{~K}$ and low saturation field measured in direction perpendicular to the substrate also revealed formation of an amorphous Fe-Ce alloys during the sample deposition. 

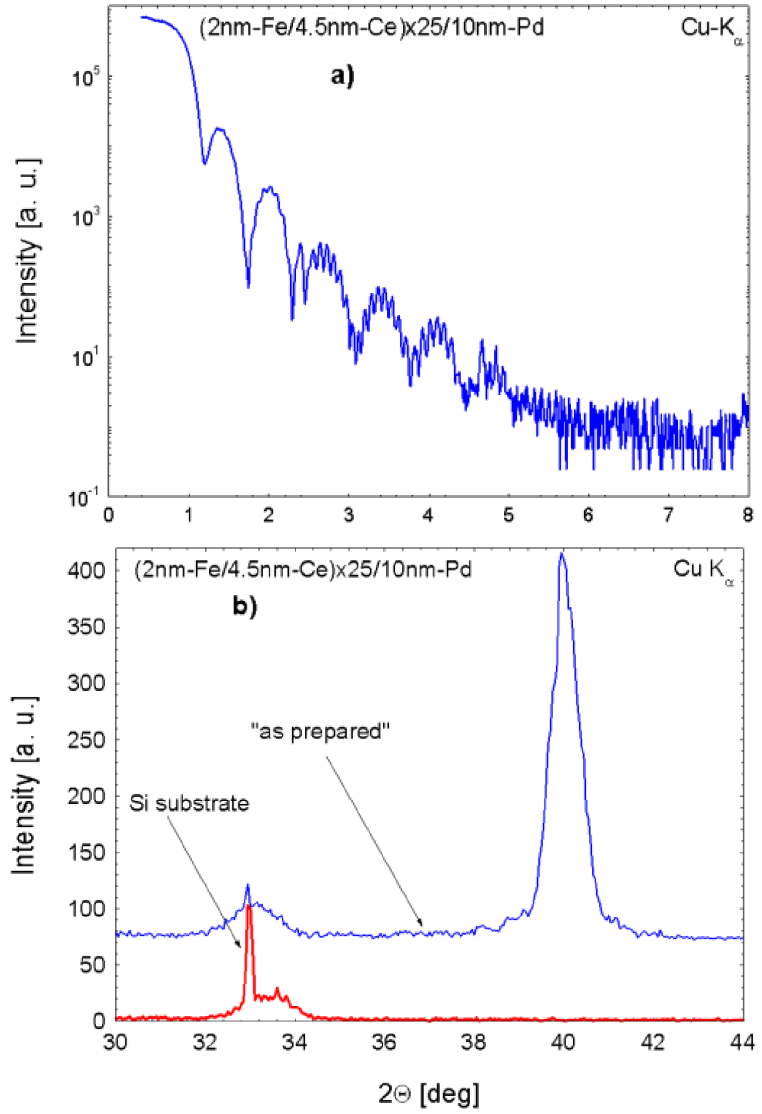

Fig. 4. Low- (a) and high-angle (b) XRD $\left(\mathrm{Cu}-\mathrm{K}_{\alpha}\right)$ pattern for $(2 \mathrm{~nm} \mathrm{Fe} / 4.5 \mathrm{~nm}-\mathrm{Ce}) \times 25 / 10 \mathrm{~nm} \mathrm{Pd}$ multilayer. For a comparison XRD pattern for $\mathrm{Si}(100)$ substrate with naturally oxidised surface is also shown in part (b).
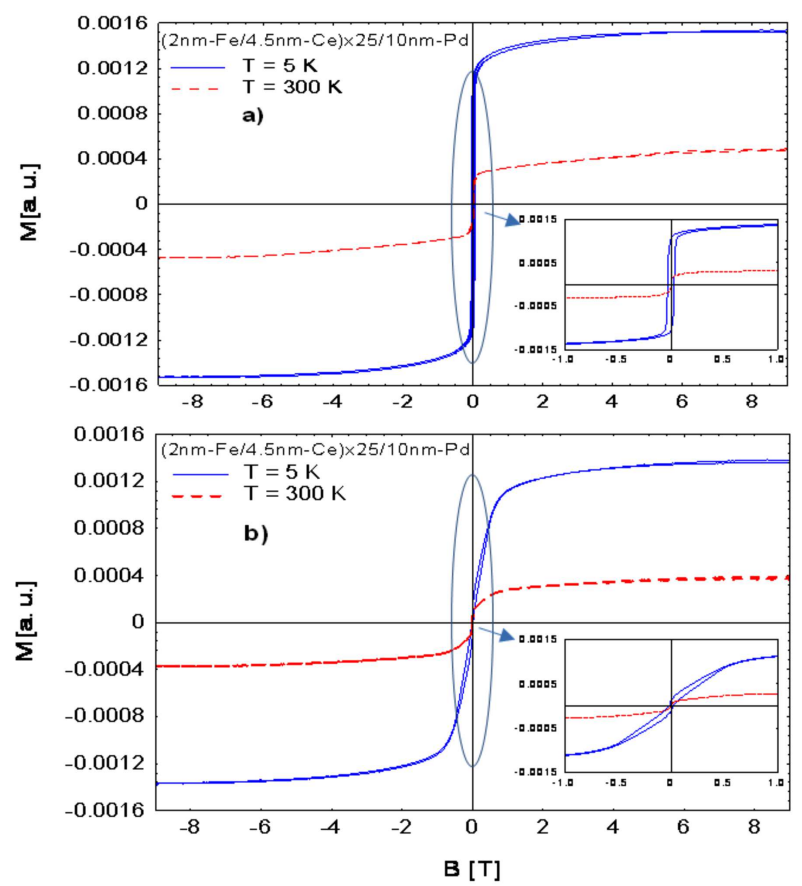

Fig. 5. Hysteresis loops measured parallel (a) and perpendicular (b) to the plane for $(2 \mathrm{~nm} \mathrm{Fe} / 4.5 \mathrm{~nm} \mathrm{Ce}) \times$ 25/10 nm Pd multilayer.

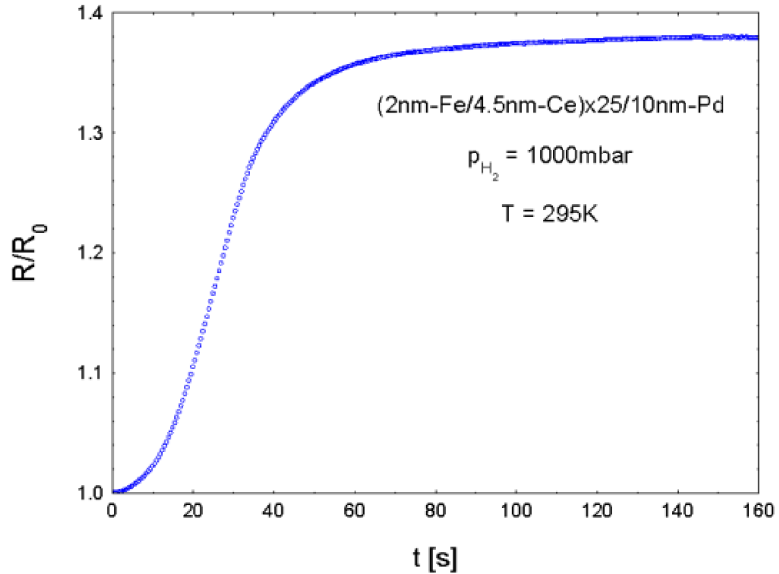

Fig. 6. Relative resistance $\left(R / R_{0}\right)$ as a function of hydrogenation time at a pressure of 1000 mbar measured at room temperature for $(2 \mathrm{~nm} \mathrm{Fe} / 4.5 \mathrm{~nm} \mathrm{Ce}) \times 25$ multilayer covered by $10 \mathrm{~nm}$ of $\mathrm{Pd}$ protective layer. $R_{0}=R(t=0)$.

In Fig. 6 we show relative resistance $\left(R / R_{0}\right)$ of the $\mathrm{Fe} / \mathrm{Ce} \mathrm{ML}$ as a function of hydrogenation time at a pressure of about 1000 mbar measured at RT. Results showed that the fastest initial rise in resistance was observed in the first $\sim 40 \mathrm{~s}$ of the hydrogenation.

In conclusion, the solid state amorphisation reaction was confirmed by XRD and magnetic measurement in the "as-prepared" Ce/Fe ML. The above results show that interdiffusion of cerium and iron is extremely fast at RT. Furthermore, it was observed a relatively fast resistivity change of the ML during the first $40 \mathrm{~s}$ of hydrogen absorption at room temperature.

\section{References}

[1] S.S.P. Parkin, Phys. Rev. Lett. 67, 3598 (1991).

[2] M. von Schilfgaarde, F. Herman, S.S.P. Parkin, J. Kudrnovskỳ, Phys. Rev. Lett. 74, 4063 (1995).

[3] S. Y. Hus, A. Barthèlèmy, P. Holody, R. Loloee, P.A. Schroeder, A. Fert, Phys. Rev. Lett. 78, 2652 (1997).

[4] M.M. Schwickert, R. Coehoorn, M.A. Tomaz, E. Mayo, D. Lederman, W.L. O'Brien, Tao Lin, G.R. Harp, Phys. Rev. B. 57, 13681 (1998).

[5] J. Izquierdo, R. Robles, A. Vega, M. Talana, C. Demangeat, Phys. Rev. B. 64, 060404 (2001).

[6] O. Eriksson, L. Nordstrom, M.S.S. Brooks, B. Johansson, Phys. Rev. Lett. 60, 2523 (1988).

[7] Vajda, in Handbook on the Physics, Chemistry of Rare Earths, Eds.: K.A. Gschneidner, L. Eyring, Elsevier, Amsterdam 1995, Vol. 20.

[8] J.N. Huiberts, R. Griessen, J.H. Rector, R.J. Wijnaarden, J.P. Dekker, D.G. de Groot, N.J. Koeman, Nature (London) 380, 231 (1996).

[9] L. Smardz, K. Le Dang, H. Niedoba, K. Chrzumnicka, J. Magn. Magn. Mater. 140-144, 569 (1995).

[10] L. Smardz, Sol. State Com. 112, 693 (1999). 
[11] L. Smardz, K. Smardz, H. Niedoba, J. Magn. Magn. Mater. 220, 175 (2000).

[12] L. Smardz, U. Kobler, W. Zinn, J. Appl. Phys. 71, 5199 (1992).

[13] J. Skoryna, S. Pacanowski, A. Marczyńska, M. Werwiński, Ł. Majchrzycki, R. Czajka, L. Smardz, Surf. Coat. Techn. 303, 125 (2016).

[14] K. Smardz, L. Smardz, I. Okonska, M. Nowak, M. Jurczyk, Int. J. Hydrog. Energy 33, 387 (2008).
[15] M. Jurczyk, L. Smardz, M. Makowiecka, E. Jankowska, K. Smardz, J. Phys. Chem. Sol. 65, 545 (2004).

[16] J. Skoryna, A. Marczyńska, L. Smardz, J. Alloys Comp. 645, S384 (2015).

[17] L. Smardz, J. Alloys Comp. 395, 17 (2005).

[18] M. Matsuura, R. Petkie, G. Singco, K.N. Tu, Mat. Sci. Eng. A 133, 551 (1991). 